WHITE PAPER

The Unprecedented Stock

Market Reaction to COVID-19

Scott R. Baker, Nicholas Bloom, Steven J. Davis, Kyle Kost, Marco Sammon, and Tasaneeya Viratyosin JUNE 2020

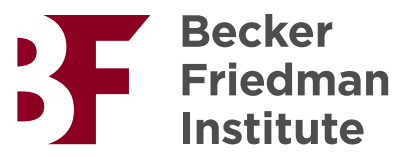




\title{
The Unprecedented Stock Market Reaction to COVID-19
}

Scott R. Baker, Nicholas Bloom, Steven J. Davis, Kyle Kost, Marco Sammon, and Tasaneeya Viratyosin 30 March 2020, Last Edited on 16 June 2020

\begin{abstract}
No previous infectious disease outbreak, including the Spanish Flu, has impacted the stock market as forcefully as the COVID-19 pandemic. In fact, previous pandemics left only mild traces on the U.S. stock market. We use text-based methods to develop these points with respect to large daily stock market moves back to 1900 and with respect to overall stock market volatility back to 1985 . We also evaluate potential explanations for the unprecedented stock market reaction to the COVID-19 pandemic. The evidence we amass suggests that government restrictions on commercial activity and voluntary social distancing, operating with powerful effects in a service-oriented economy, are the main reasons the U.S. stock market reacted so much more forcefully to COVID-19 than to previous pandemics in 1918-19, 1957-58 and 1968.

JEL Numbers: E44, E65, G12, G18, I18

Contact Information: srbaker@gmail.com, nbloom@stanford.edu,

Steven.Davis@,chicagobooth.edu,kkost84@gmail.com, mcsammon@gmail.com and virat003@morris.umn.edu.

Acknowledgements: We gratefully acknowledge financial support from the U.S. National Science Foundation (SES 1324257) and the University of Chicago Booth School of Business. We thank the editor and an anonymous referee for helpful comments on an earlier draft. Data on our newspaper-based classifications of daily stock market jumps are available at https://stockmarketjumps.com. Data for our newspaper-based Equity Market Volatility Tracker and Infectious Disease Equity Market Volatility Tracker are available at http://www.policyuncertainty.com.
\end{abstract}


As the Novel Coronavirus (COVID-19) spread from a regional crisis in China's Hubei Province to a global pandemic, equities plummeted and market volatility rocketed upwards around the world. In the United States, volatility levels in the middle of March 2020 rival or surpass those last seen in October 1987 and December 2008 and, before that, in late 1929 and the early 1930s (Figure 1). Volatility began to retreat in the latter part of March 2020 and, by late April, fell sharply but remained well above pre-pandemic levels. Motivated by these observations, we examine the role of COVID-19 developments in recent stock market behavior and draw comparisons to previous infectious disease outbreaks.

To quantify the role of news about infectious disease outbreaks, we use both automated and human readings of newspaper articles. Looking back to 1985, we find no other infectious disease outbreak that had more than a tiny effect on U.S. stock market volatility. Looking back to 1900, we find not a single instance in which contemporaneous newspaper accounts attribute a large daily market move to pandemic-related developments. That includes the Spanish Flu of 1918-20, which killed an estimated 2.0 percent of the world's population (Barro, Ursua and Weng, 2020). It also includes the influenza pandemics of 1957-58 and 1968, which led to excess mortality rates in the United States roughly three times as high as the experience to date with COVID-19. In striking contrast, news related to COVID-19 - both positive and negative - is the dominant driver of large daily U.S. stock market moves from 24 February 2020 through April 2020, when our sample ends. The frequency of large daily stock market moves during this period is also exceptional.

Lastly, we consider potential explanations for the stock market reaction to COVID-19, which is extraordinary in absolute terms and relative to previous pandemics in 1918-19, 1957-58 and 1968. The evidence we amass rules out certain seemingly plausible explanations, including those that simply stress the lethality and adverse health effects of the coronavirus. The timing of large stock market moves during 2020 is hard to square with explanations that stress disruptions to cross-border supply chains. Our preferred explanation stresses mandatory business closures, other restrictions on commercial activity, and voluntary social distancing - including the powerful effects of these policies and behaviors in a service-oriented economy. Government restrictions on commercial activity in response to COVID-19 are more stringent, broader in scope, more widespread, and lengthier in duration than policy responses to the Spanish Flu and completely unlike the governmental response to the 1957-58 and 1968 influenza pandemics. 


\section{Characterizing Daily Stock Market Jumps}

In Baker, Bloom, Davis and Sammon (2019), we examine next-day newspaper explanations for each daily move in the U.S. stock market greater than 2.5 percent, up or down. By this criterion, there were 1,143 stock market jumps from 2 January 1900 to 30 April 2020. While these days make up only $3.5 \%$ of all trading days in this time period, they are highly impactful in terms of overall market movements, constituting $47 \%$ of total squared daily return variation in the past 120 years.

To characterize these jumps, we read the lead article about each jump in next-day newspapers (or the same evening in the internet era) to classify the journalist's explanation into one of 16 categories, which include Macroeconomic News and Outlook, Government Spending, Monetary Policy, Unknown or No Explanation Offered, and Other - Specify. Our coding guide in Baker, Bloom, Davis and Sammon (2018) describes the methodology in detail.

Table 1 draws on our classification effort to underscore the unprecedented impact of the COVID-19 pandemic on the U.S. stock market. In the period before 24 February 2020 spanning 120 years and more than 1,100 jumps - contemporary journalistic accounts attributed not a single daily stock market jump to infectious disease outbreaks or policy responses to such outbreaks. ${ }^{1}$ Perhaps surprisingly, even the Spanish Flu fails to register in next-day journalistic explanations for large daily stock market moves. There were 23 daily stock market jumps from March 1918 to June 2020, which spans the three major waves of the Spanish Flu.

If we consider a longer span from January 1918 to December 1920, we find 4 jumps before Germany signed an armistice agreement with the allies on 11 November 1918 and 7 jumps before the signing of the Treaty of Versailles on 28 June 1919. Next-day accounts in the Wall Street Journal attribute 4 of these 7 jumps primarily or secondarily to war-related developments. They also attribute jumps on 21 July and 28 November in 1919 secondarily to war-related developments. From the armistice agreement through the end of 1920, next-day accounts in the Wall Street Journal attribute 11 of 28 jumps to Macroeconomic News and

\footnotetext{
${ }^{1}$ Originally, we did not record whether journalistic accounts attributed specific jumps to policy responses to infectious disease outbreaks, although we allowed for two catchall categories: Other Policy Matters Specify and Other Non-Policy Matters - Specify. In preparing this paper, we reread all lead newspaper articles about stock market jumps from January 1918 to December 1920 to confirm we had not overlooked jump explanations attributed to the Spanish Flu.
} 
Outlook (primarily or exclusively) and the rest to a wide range of categories that include Monetary Policy and Central Banking, Corporate Earnings, Taxes, Trade Policy, and Regulation. For 7 jumps during the period, next-day accounts in the Wall Street Journal offer no explanation or explicitly state that the reason for the jump is unknown.

Turning to other pandemics, the U.S. Center for Disease Control estimates that the 195758 and 1968 influenza pandemics caused 116,000 and 100,000 excess deaths, respectively, in the United States. $^{2}$ Scaling by population yields excess mortality rates of 0.067 percent in 1957-58 and 0.050 percent in 1968 . As of 1 June 2020, the U.S. excess mortality rate during the COVID19 episode is $(71,500 / 326.69$ million $)=0.02$ percent of the population. ${ }^{3}$ Thus, if the COVID-19 death toll in the United States ultimately triples, it will reach excess mortality rates comparable to the experiences in 1957-58 and 1968. There were 9 jumps in 1957-58 and one in 1968. Nextday accounts in the Wall Street Journal attribute none to pandemic-related developments. ${ }^{4}$

Data since late February 2020 tell a remarkably different story. In the period from 24 February to 24 March 2020, there were 22 trading days and 18 market jumps - more than any other period in history with the same number of trading days. Jump frequency during this period is over 20 times the average pace since 1900. From February 24 through the end of April, there were 27 jumps. Next-day newspaper accounts attribute 23 or 24 of them to news about COVID19 developments and policy responses to the pandemic. ${ }^{5}$

In short, no previous infectious disease episode led to daily stock market swings that even remotely resemble the response in 2020 to COVID-19 developments. While other periods have seen large declines or increases in equity markets over periods of several weeks or months, the

\footnotetext{
${ }^{2}$ See www.cdc.gov/flu/pandemic-resources/1957-1958-pandemic.html and www.cdc.gov/flu/pandemicresources/1968-pandemic.html. Glezen (1996) reports similar estimates for excess mortality in the 195758 and 1968 pandemics and discusses the concept of excess mortality.

${ }^{3}$ The excess mortality figure is from www.ft.com/content/a26fbf7e-48f8-11ea-aeb3-955839e06441, accessed 1 June 2020, and the population figure is from the World Bank at https://data.worldbank.org/indicator/SP.POP.TOTL.

${ }^{4}$ Sovereign Military and Security Actions account for 3 of these 10 jumps, Elections and Political Transitions Account for 2, Unkown and No Explanation Offered account for 2, and the rest are scattered across several categories.

${ }^{5}$ The New York Times offered no clear explanation for the downward jump on 20 March, while the Wall Street Journal attributed it to pandemic-related policy responses. Both papers attributed the upward jump on 4 March to Elections and Political Transitions (i.e., Biden's strong showing in primary elections) and the downward jump on 9 March 2020 to Commodity Markets. Both papers attributed all other jumps since 24 February to COVID-19 developments or policy responses thereto.
} 
COVID-19 period stands out for an extremely high frequency of large daily stock market moves. And, as we have stressed, there is no previous episode in the past 120 years in which pandemicrelated developments drove any large daily stock market moves, let alone the 24 jumps that our newspaper-based analysis attributes to pandemic-related developments in the ten-week period commencing on 24 February 2020.

It's worth stressing that large daily stock market moves during this period were in both directions. Indeed, the S\&P 500 index plunged 33 percent from 21 February to its trough on 23 March. ${ }^{6}$ It then rose 30 percent from its bottom by the last trading day in April, the end of our sample period. Our analysis considers both negative and positive jumps in response to news about COVID-19 and policy responses as drivers of the stock market.

\section{Quantifying the Contribution of COVID-19 to Overall U.S. Stock Market Volatility}

As in Baker, Bloom, Davis, and Kost (2019), we use a mechanized approach to quantify the role of COVID-19 and other infectious diseases in U.S. stock market volatility. In a first step, we calculate the monthly fraction of articles in 11 major US newspapers that contain (a) terms related to the economy, (b) terms related to equity markets, and (c) terms related to market volatility. We multiplicatively rescale this monthly series to match the mean value of the VIX since 1985. Figure 2 plots our resulting newspaper-based Equity Market Volatility (EMV) tracker alongside the VIX itself, with an inset showing recent data at a weekly frequency. As the figure shows, our EMV tracker performs well in the sense of mirroring the time-series behavior of implied stock market volatility. The same is true with respect to realized stock market volatility, as shown by Baker, Bloom, Davis and Kost.

In a second step, we identify the subset of EMV articles that contain one or more terms related to COVID-19 or other infectious diseases. Specifically, we flag EMV articles that mention one of the following terms: epidemic, pandemic, virus, flu, disease, coronavirus, MERS, SARS, Ebola, H5N1, or H1N1. Multiplying the fraction of EMV articles that contain one of these terms by our EMV tracker yields our Infectious Disease EMV tracker displayed in Figure 3. The inset part displays the results of the same quantification exercise at a weekly frequency.

\footnotetext{
${ }^{6}$ The S\&P 500 index value on 21 February is slightly below the pre-pandemic peak. We select the closing price on 21 February as the starting point, because it is the last trading day before the first market jump that contemporaneous newspaper accounts attribute to COVID-19.
} 
Figure 3 makes three points. First, before the COVID-19 pandemic, no infectious disease outbreak made a sizable contribution to U.S. stock market volatility. The 2003 SARS epidemic and the 2015 Ebola epidemic led to modest, short-lived spikes in volatility, and the Bird Flu and Swine Flu epidemics barely registered. Second, the COVID-19 pandemic drove the tremendous recent surge in stock market volatility. Recall from Figure 1 that this surge led to the third highest realized volatility peak since 1900 . So, the volatility peak is extraordinarily high by historical standards (Figure 1), and it's almost entirely triggered by COVID-19 developments, including policy responses to the pandemic. Third, the COVID-19 volatility surge began in the fourth week of January, intensified from the fourth week of February, and began tapering in the fourth week of March. By the last week of April, our Infectious Disease EMV tracker had fallen to less than half its peak levels in March, but it remains far above pre-COVID levels.

Table 2 provides more information about newspaper coverage of various infectious disease outbreaks since 1985. For each episode, we report the mean value of our Infectious Disease EMV tracker, the fraction of EMV articles that contains one of our infectious disease terms (as listed above), and the fraction of articles about Economic Policy Uncertainty (EPU) that contains one of those terms. Here, we use the EPU index developed by Baker, Bloom and Davis (2016). The bottom row shows averages for the full period from January 1985 to April 2020.

By these metrics, the early-phase impact of COVID-19 looks similar to the impact of other infectious disease outbreaks in the past 35 years. In January 2020, for example, the Infectious Disease EMV tracker is only modestly elevated, and the percent of EMV and EPU articles that discuss COVID-19 developments is roughly in line with previous experiences during the SARS and Ebola epidemics. By February, however, COVID-19 developments began to dominate newspaper coverage of stock market volatility and figure prominently in newspaper discussions of economic policy uncertainty. By March, COVID-19 developments receive attention in more than $90 \%$ of all newspaper discussions of market volatility and policy uncertainty, and this pattern persists through April. These data confirm the unprecedented impact of the COVID-19 pandemic as a driver of U.S. stock market volatility. 


\section{Why Such Powerful Stock Market Effects?}

Why have COVID-19 developments exerted such powerful effects on the stock market since late February? Clearly, the current pandemic has grave implications for public health. So, part of the answer surely lies in the severity of the COVID-19 pandemic, the apparent ease with which the virus spreads, and the non-negligible mortality rate among those who contract it. However, this answer is highly incomplete. The excess mortality rate during the COVID-19 pandemic is currently only $1 / 25^{\text {th }}$ as large as the rate during the Spanish Flu. ${ }^{7}$ Nevertheless, as Table 1 shows, the Spanish Flu triggered not a single daily stock market move of 2.5 percent or more, while developments related to COVID-19 triggered two dozen such jumps.

The Spanish Flu unfolded in a very different social, political, and economic context than the current pandemic. Agriculture and Manufacturing accounted for 61 percent of employment then, as compared to 10 percent now (Velde, 2020). The first wave of the Spanish Flu in Spring 1918 occurred during the last stages of World War I, and the deadlier second wave from September 1918 to February 1919 overlapped with the end of the war and the demobilization of troops. These contemporaneous developments complicate efforts to assess the economic effects of the Spanish Flu. Partly to address this challenge, Velde (2020) draws on a variety of high-frequency data to assess the short-term economic impact of the Spanish Flu in the United States. He concludes that "the pandemic coincided with, and very likely contributed to a mild recession from which the economy quickly rebounded." Thus, his analysis only sharpens the contrast between the modest economic fallout of the Spanish Flu and the huge contraction in the wake of the far less lethal COVID-19 pandemic.

As we remarked earlier, U.S. excess mortality rates during the 1957-58 and 1968 influenza pandemics were 3.3 and 2.5 times as large, respectively, as the excess mortality rate to date under COVID-19. Yet, as Ferguson (2020) underscores, the 1957-58 pandemic imparted only a mild impact on aggregate economic activity, and it was not seen as a significant macroeconomic factor by contemporaneous observers. His conclusion is consistent with the absence of large daily stock market moves in reaction to the influenza pandemic in 1957-58. Similarly, US employment and output grew at a healthy pace during 1968, showing no visible

\footnotetext{
${ }^{7}$ Barro, Ursua and Weng (2020) report a U.S. excess mortality rate of 0.52 percent of the population from 1918 to 1920 , as compared to 0.02 percent during the COVID-19 pandemic using our calculation above.
} 
reaction to the influenza pandemic. The stock market was quiescent, experiencing only a single large daily jump in 1968. These more recent pandemics also offer a startling contrast to the enormous stock market reaction and economic contraction triggered by COVID-19. ${ }^{8}$

A second potential answer, particularly in comparison to the Spanish Flu, is that information about pandemics is richer and diffuses much more rapidly now than a century earlier. ${ }^{9}$ According to this explanation, the stock market impact of the COVID-19 pandemic is more temporally concentrated and more likely to trigger daily stock market jumps and high stock market volatility than Spanish Flu developments a century earlier. As Velde (2020) discusses, however, the negative stock market impact of the Spanish Flu was fairly modest even over time spans of weeks and months. The Dow-Jones Index actually rose over most of 1918 and 1919, reaching a peak in October 1919. The index then fell by nearly half, mostly during the recession that unfolded from January 1920 to July $1921{ }^{10}$ This recession and coincident stock market decline had little to do with the Spanish Flu. In her analysis of the 1920-1921 recession, Romer (1988) does not mention the Spanish Flu. Hence, explanations that stress greater information availability and its more rapid diffusion to market participants cannot rationalize the huge stock market reaction to COVID-19, especially as compared to the mild stock market effects of the Spanish Flu.

A third explanation stresses the role of cross-border flows of goods in the modern economy, driven by decades of falling transport costs, falling communication costs and, until recently, falling tariffs. These developments led to heavy reliance on geographically expansive supply chains and the ubiquity of just-in-time inventory systems. ${ }^{11}$ Both are highly vulnerable to sudden supply disruptions. Thus, it is natural to ask whether stock markets reacted so forcefully to COVID-19 because of its potential to disrupt cross-border supply chains.

\footnotetext{
${ }^{8} \mathrm{We}$ focuse on the US experience, but the size of the COVID-19 mortality shock to date varies greatly among advanced economies. In the United Kingdom, one of the worst-hit countries, COVID-19 has caused an estimated 59,500 excess deaths to date and an excess mortality rate of about 0.09 percent of the population. By way of comparison, Germany has an excess mortality rate of only 0.009 percent. See footnote 6 for data sources.

${ }^{9}$ As a related point, the first wave of the Spanish Flu occurred during World War I when news about the true extent of the outbreak was censored (Honigsbaum, 2013).

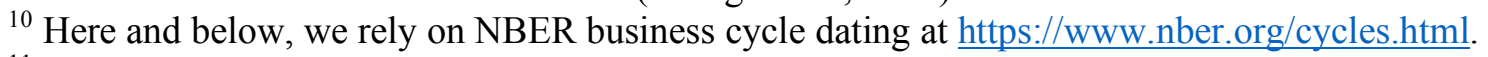

${ }^{11}$ On supply chains, see Baldwin and Tomiura (2020) and on falling trade costs, see Jacks, Meissner and Novy (2011).
} 
COVID-19 effects on the U.S. stock market were highly muted in the period before significant outbreaks in the United States, despite a major pandemic in several other countries, most notably China. This observation about timing casts doubt on the importance of international supply-chain disruptions as a major force in the powerful U.S. stock market reactions to COVID19 developments. If imperiled supply chains were a major driver of stock market volatility, we would expect to see strong market reactions sooner, when China and parts of Europe undertook social distancing, quarantine, and market shutdown measures that sharply curtailed their production. While disruptions to international supply chains surely have contributed to a contraction in economic activity, the timing evidence suggests they are not the main driver of U.S. stock market jumps and overall market volatility since late February. ${ }^{12}$

Two other explanations also stress prominent features of the economy circa 2019 that distinguish it from the economy of 1918, 1957 or 1968: high-volume international travel and the predominant role of the service sector. Long-distance travel has become commonplace, supporting tourism and hospitality sectors and facilitating interactions and commercial activity in business, entertainment, education, and the sciences. ${ }^{13}$ The structure of the economy has also shifted over time to consumer and business services, which often involve face-to-face interactions in close physical proximity. An abrupt uptake of voluntary and compulsory social distancing practices brings a sharp drop in demand for such services. We will return shortly to the impact of travel restrictions and the curtailment of face-to-face interactions in the commercial sphere.

That brings us to nonpharmaceutical policy interventions (NPIs) that aim to slow or contain the COVID-19 pandemic. Consider travel restrictions, one type of NPI. As of 15 June 2020, the United States has restricted travel from China since 2 February, Iran (2 March), 26 European countries in the Schengen area (17 March), the United Kingdom and Ireland (19 March), Mexico and Canada (19 May), and Brazil (24 May). The restrictions route flights from

\footnotetext{
${ }^{12}$ A separate question is whether reliance on, and disruptions to, international supply chains are important drivers of heterogeneity in firm-level stock returns during 2020. Davis, Hansen and Seminario (2020) and Ramelli and Wagner (2020) trace the COVID-induced heterogeneity in firm-level stock returns to specific risk exposure categories such as reliance on global supply chains, exports to China, food and drug regulation, energy regulation, and financial regulation. Unlike those papers, our focus is on overall market-level moves.

${ }^{13}$ For Europe, cross-border commuting has also become an integral part of how economies function (Meninno and Wolf, 2020).
} 
affected countries to a limited number of designated U.S. airports, and they prohibit entry by most foreign nationals who visited any country on the restricted list within the previous 14 days. ${ }^{14}$ In Figure 4, we show that relative to a year earlier, the weekly frequency of international flights fell 75 percent from mid-March to early May. The global fall is similar, whereas the pattern for China shows a much earlier and steeper drop followed by a considerable recovery. These data understate the drop in international air travel, because they do not account for declines in passengers per flight during the coronavirus pandemic. ${ }^{15}$

Gupta et al. (2020b, Figure 2.1) quantify several other types of government-mandated NPIs in the United States, which proliferated rapidly from the middle of March 2020. By late March, nearly 100 percent of U.S. residents lived in counties where state or local officials had closed schools and dine-in restaurants, roughly 70 percent lived in counties with mandatory closures of non-essential businesses, and roughly 90 percent were subject to stay-at-home orders and bans on public gatherings. Most states began to relax some of their social distancing requirements by early May (Nguyen et al, 2020), but major restrictions remain in place as of early June in much of the country. Finally, generous unemployment benefits under the Coronavirus Aid, Relief, and Economic Security (CARES) Act effectively subsidize social distancing by making it financially costly for most job losers to return to work before 1 August. ${ }^{16}$

These interventions to combat COVID-19 are more aggressive, broader in scope, more widespread geographically, and lengthier than NPIs adopted during the Spanish Flu. Markel et al. (2007) consider NPIs in 43 American cities (accounting for 22 percent of the U.S. population)

\footnotetext{
${ }^{14}$ See the U.S. Department of Homeland Security announcements at www.dhs.gov/publication/noticesarrival-restrictions-coronavirus and www.dhs.gov/publication/notification-temporary-travel-restrictionsapplicable-land-ports-entry-and-ferries, the White House proclamation at www.whitehouse.gov/presidential-actions/proclamation-suspension-entry-immigrants-nonimmigrantscertain-additional-persons-pose-risk-transmitting-novel-coronavirus/, and the Center for Disease Control statement at www.cdc.gov/coronavirus/2019-ncov/travelers/from-other-countries.html.

${ }^{15}$ We can quantify the overall drop in commercial air travel in the United States using TSA data on "Total Traveler Throughput" at www.tsa.gov/coronavirus/passenger-throughput. According to these data, air travel is down 93 percent from a year earlier on 31 March 2020 and 94 percent on 30 April.

${ }^{16}$ President Trump signed the CARES Act on 27 March 2020. As part of this relief act, the federal government supplements unemployment benefit levels by $\$ 600$ per week through the end of July 2020. Ganong, Noel and Vavra (2020) estimate that the median replacement rate for unemployment benefit recipients is 134 percent under the CARES Act. They also estimate that two-thirds of eligible workers receive benefits that exceed lost earnings, and one-fifth receive benefits that are at least twice as high as lost earnings.
} 
from 18 September 1918 to 22 February 1919. They group NPIs into three main categories: school closures, cancellation of public gatherings, and isolation and quarantine mandates. The most common NPI regime (34 cities) involved school closures and bans on public gatherings for a median duration of four weeks. Bootsma and Ferguson (2007), who consider NPIs in 23 American cities, state that a "range of interventions was tried in the U.S. in 1918, including closure of schools and churches, banning of mass gatherings, mandated mask wearing, case isolation, and disinfection/hygiene measures." Broad travel restrictions and widespread business closures do not figure in their discussion. Hatchett, Mecher and Lipsitch (2007) offer a similar account and note that "few cities maintained NPIs longer than six weeks in 1918." Only one city among the 17 in their sample implemented community-wide business closures.

Governmental authorities in the United States refrained from NPIs in response to the 1957-58 influenza pandemic (Henderson et al., 2009 and Ferguson, 2020). As Henderson et al. (2009, p. 270) put it, "Measures were generally not taken to close schools, restrict travel, close borders, or recommend wearing masks. Quarantine was not considered to be an effective mitigation strategy." The focus was instead on surveillance, rapid vaccine development and, once developed, its priority deployment to healthcare workers, persons providing basic community services, and persons at high health risk from the virus. Those who contracted the virus were encouraged to rely on home health care except in cases involving complications or aggravating conditions. At a special meeting of the Association of State and Territorial Health Officers held in Washington, DC on 27-28 August, the members resolved that "there is no practical advantage in the closing of schools or the curtailment of public gatherings as it relates to the spread of this disease" (as quoted in Henderson et al., 2009). Schools experienced high absenteeism rates during the peak of the pandemic, as did healthcare workers and teachers, and some high school and college football games were cancelled or postponed.

This brief review makes clear that the aggressive, widespread implementation of NPIs during the 2020 coronavirus pandemic is much more severe and far-reaching than measures adopted during the Spanish Flu and completely unlike the U.S. approach during the 1957-58 influenza pandemic. Indeed, we are unaware of any previous pandemic in U.S. history that prompted such an aggressive use of NPIs. Thus, it appears that the heavy use of NPIs during the 2020 coronavirus pandemic is also unprecedented in U.S. history. 
These interventions in combination with voluntary social distancing responses to the pandemic have drastically curtailed economic activity in the United States. As Baldwin (2020) puts it, "COVID-19 and the containment policies have directly and massively reduced the flow of labour to businesses. The result has been a sudden and massive reduction in the output of goods and services." We would add that containment policies have also massively reduced the flow of customers to business premises, bringing huge revenue reductions to other than online businesses and delivery services.

To be sure, government-mandated restrictions are far from the whole explanation for the curtailment of economic activity during the COVID-19 pandemic. Recent research by Maloney and Taskin (2020) and Gupta et al. (2020b) finds that voluntary social distancing - often prompted by first-case announcements, emergency declarations, and other information-oriented government actions - have been at least as important as government mandates in reducing individual mobility, work activity on business premises, and customer visits to restaurants, retail outlets and other businesses. Farboodi, Jarosch and Shimer (2020) incorporate individual optimizing behavior into a canonical epidemiological model. They argue that the decentralized equilibrium version of their model yields voluntary declines in social activity similar to the actual declines observed in data for the United States.

Like government-mandated restrictions on commercial activity, voluntary socialdistancing actions have potent effects on economic activity. Their effects are especially powerful in a service-oriented economy that involves extensive face-to-face encounters in restaurants, shopping malls retail outlets, entertainment venues, professional and business services, personal services, educational institutions and healthcare facilities as well as among employees in the workplace. See Coibion et al. (2020) and Gupta et al. (2020b) for early causal evidence on the negative economic effects of stay-at-home mandates and forced business closures during the 2020 coronavirus pandemic.

\section{Concluding Remarks}

We have shown that the effects of COVID-19 developments and policy responses on the U.S. stock market are without historical precedent. There were more than 1,100 daily stock market moves (up or down) greater than 2.5 percent from 1900 to 2019. Next-day newspaper accounts attribute not a single one of these jumps to infectious disease outbreaks or pandemic- 
related developments. From 24 February to 20 April 2020, newspapers attribute two dozen such jumps to coronavirus-related developments. A similar pattern holds for measures of real economic activity. Compared to the 2020 pandemic, even the Spanish Flu of 1918-19 had modest effects on the U.S. economy. The influenza pandemic of 1957-58 left weak marks on the economy and the 1968 pandemic left no apparent trace.

Our comparisons to the 1918-19,1957-58 and 1968 show that the unprecedented stock market reaction to COVID-19 cannot be explained simply by the lethality of the virus. To date, the excess mortality rate from COVID-19 is only $1 / 25^{\text {th }}$ as large as the rate during the Spanish Flu. The influenza pandemics of 1957-58 and 1968 led to excess mortality rates roughly three times that of COVID-19. Of course, COVID-19 deaths would be higher if governmental authorities in 2020 had adopted the more laissez-faire approach taken in 1957-58 and 1968, or even the strategy of relatively limited and localized NPIs pursued in 1918-19. We also find little support for explanations that stress more rapid information diffusion in today's economy and explanations that stress the role of disruptions to international supply chains.

More promising explanations focus on the role of government restrictions on individual mobility and commercial activity plus voluntary social distancing - all of which have powerful effects in a service-oriented economy. Government-mandated NPIs during the COVID-19 pandemic have taken several forms: restrictions on international travel, school closures, stay-athome orders, bans on public gatherings, closures of non-essential businesses, and mandates to wear masks and maintain social distancing. The earliest stock market jumps attributed to COVID-19 developments in late February and early March mostly involve reactions to news about the course of the pandemic in the United States. Jumps later in March and through the end of April 2020 also reflect policy responses to the pandemic, including news about actual or prospective fiscal and monetary policy actions.

We recognize that our conclusions about the reasons for the extraordinary stock market reaction to COVID-19 have a broad-brush character. There is much room for further investigation into the relative importance of voluntary social distancing efforts and government restrictions, as well as studies that seek to quantify the role of particular restrictions. There is also much room for research into the stock market reactions to particular fiscal and monetary policy actions during the 2020 pandemic. 
As a final remark, we think our evidence offers grounds for reflection on the wisdom of heavy-handed restrictions on commercial activity in efforts to contain the coronavirus pandemic. The healthcare rationale for travel restrictions, business closures, and social distancing mandates is clear. By now, it is also painfully evident that these policies bring great economic damage. There is a compelling need to address the health crisis created by COVID-19 while shifting to less sweeping containment policies that do not strangle the economy, as argued by Cochrane (2020), Dewatripont et al. (2020), Fujita et al. (2020), Ichino et al. (2020) and Monras (2020), among others. 


\section{References}

Association of State and Territorial Health Officers, 1957. "Resolutions Adopted by Association of State and Territorial Health Officers at Special Meeting on Influenza, Washington D.C," an appendix to CDC Influenza Report No. 14, 29 August.

Baker, Scott, Nicholas Bloom and Steven J. Davis, 2016. "Measuring Economic Policy Uncertainty," Quarterly Journal of Economics, November.

Baker, Scott Baker, Nicholas Bloom, Steven J. Davis and Kyle Kost, 2019. "Policy News and Equity Market Volatility," NBER working paper.

Baker, Scott Baker, Nicholas Bloom, Steven J. Davis and Marco Sammon, 2018. Coding Large Daily Financial Market Moves: Data Construction Guide. Available at https://stockmarketjumps.com/files/coding_guide_pdf.pdf.

Baker, Scott Baker, Nicholas Bloom, Steven J. Davis and Marco Sammon, 2019. "What Triggers Stock Market Jumps?” working paper.

Baldwin, Richard, 2020. “The Supply Side Matters: Guns versus Butter, COVID-Style,” VOX CEPR Policy Portal, 22 March.

Baldwin, Richard and Eiichi Tomiura, 2020. "Thinking Ahead about the Trade Impact of COVID-19," in Economics in the Time of COVID-19, edited by Richard Baldwin and Beatrice Weder di Mauro. CEPR Press.

Barro, Robert J., Jose F. Ursua and Joanna Weng, 2020. “The Coronovirus and the Great Influenza Pandemic - Lessons from the 'Spanish Flu' for the Coronavirus's Potential Effects on Mortality and Economic Activity,” CESifo Working Paper No. 8166.

Bootsma, Martin C.J. and Neil M. Ferguson, 2007, "The Effect of Public Health Measures on the 1918 Influenza Pandemic in U.S. Cities," Proceedings of the National Academies of Sciences, 104, no. 18 (April), 7588-7593.

Cochrane, John H., 2020. "Flatten the Coronavirus Curve at a Lower Costs," Wall Street Journal, 25 March.

Coibion, Olivier, Yuriy Gorodnichenko and Michael Weber, 2020. "The Cost of the COVID-19 Crisis: Lockdowns, Macroeconomic Expectations, and Consumer Spending,” NBER Working Paper 27141.

Davis, Steven J., Stephen Hansen and Cristhian Seminario, 2020. "Firm-Level Risk Exposures and Stock Price Reactions to COVID-19," working paper. 
Dewatripont, Mathias, Michel Goldman, Eric Muraille and Jean-Philippe Platteau, 2020.

"Rapidly Identifying Workers Who Are Immune to COVID-19 and Virus-Free Is a Priority for Restarting the Economy," VOX CEPR Policy Portal, 23 March.

Farboodi, Maryam, Gregor Jarosch, and Robert Shimer, 2020. "Internal and External Effects of Social Distancing in a Pandemic,” NBER Working Paper 27059.

Ferguson, Niall, 2020. "1918, 1957, 2020: Big Pandemics and their Economic, Social and Political Consequences," working paper, 20 May.

Fujita, Shigeru, Giuseppe Moscarini and Fabien Postel-Vinay, 2020. "The Labour Market Policy Response to COVID-19 Must Leverage the Power of Age," VOX CEPER Policy Portal, 15 May 2020.

Ganong, Peter, Pascal Noel and Joseph Vavra, 2020. "Unemployment Insurance Replacement Rates During the Pandemic,” NBER Working Paper 27216.

Glezen, W. Paul, 1996. “Emerging Infections: Pandemic Influenza," Epidemiologic Review, 18, no. 1, 64-76.

Gupta, Sumedha, Laura Montenovo, Thuy D. Nguyen, Felipe L. Rojas, Ian M. Schmutte, Kosali I. Simon, Bruce A. Weinberg and Coady Wing, 2020a. "Effects of Social Distancing Policy on Labor Markets,” NBER Working Paper 27280.

Gupta, Sumedha, Thuy D. Nguyen, Felipe L. Rojas, Shyam Raman, Byungkyu Lee, Ana Bento, Kosali I. Simon and Coady Wing, 2020b. "Tracking Public and Private Responses to the COVID-19 Epidemic: Evidence from State and Local Government Actions," NBER Working Paper 27027.

Hatchett, Richard J., Carter E. Mecher and Marc Lipsitch, 2007. "Public Health Interventions and Epidemic Intensity During the 1918 Influenza Pandemic," Proceedings of the National Academies of Sciences, 104, no. 18 (April), 7582-7587.

Henderson, D.A., Brooke Courtney, Thomas V. Inglesby, Eric Toner and Jennifer B. Nuzzo, 2009. "Public Health and Medical Responses to the 1957-58 Influenza Pandemic," Biosecurity and Bioterrorism: Biodefense Strategy, Practice, and Science, 7, no. 3 (October), 265-273.

Honigsbaum, Mark. "Regulating the 1918-19 pandemic: Flu, stoicism and the Northcliffe press." Medical history 57.2 (2013): 165-185. 
Ichino, Andreas, Giacomo Calzolari, Andrea Mattozzi, Aldo Rustichini, Giulio Zanella, and Massimo Arnelli, 2020. "Transition Steps to Stop COVID-19 without Killing the World Economy," VOX CEPR Policy Portal, 25 March.

Jacks, David S., Christopher M. Meissner and Dennis Novy, 2011. "Trade Booms, Trade Busts, and Trade Costs," Journal of International Economics, 83, no. 2 (March).

Maloney, William and Temel Taskin, 2020. "Determinants of Social Distancing and Economic Activity During COVID-19: A Global View," working paper, 7 May.

Markel, Howard, Harvey B. Lipman, J. Alexander Navarro, Alexandra Sloan, Joseph R. Michalsen, Alexandra Minna Stern, and Martin S. Cetron, 2007. "Nonpharmaceutical Interventions Implemented by U.S. Cities During the 1918-19 Influenza Pandemic," Journal of the American Medical Association, 298, no. 6 (August), 644-654.

Meninno, Raffaella and Guntram Wolff, 2020. "As Coronavirus Spreads, Can the EU Afford to Close Its Borders?" in Economics in the Time of COVID-19, edited by Richard Baldwin and Beatrice Weder di Mauro. CEPR Press.

Monras, Joan, 2020. "Some Thoughts on COVID-19 from a Labour Mobility Perspective: From 'red-zoning' to 'green-zoning'," VOX CEPR Policy Portal, 25 March.

Nguyen, Thuy D., Sumedha Gupta, Martin Andersen, Ana Bento, Kosali I. Simon and Coady Wing, 2020. "Impacts of State Reopening Policy on Human Mobility," NBER Working Paper No. 27235.

Ramelli, Stefano and Alexander F. Wagner, 2020. "Feverish Stock Price Reactions to COVID19,” Swiss Finance Institute Research Paper No. 20-12, 21 April.

Romer, Christina D., 1988. "World War I and the postwar depression: A reinterpretation based on alternative estimates of GNP" Journal of Monetary Economics 22, No. 1: 91-115.

Velde, Francois, 2020. "What Happened to the US Economy During the 1918 Influenza Pandemic? A View Through High-Frequency Data," Federal Reserve Bank of Chicago Working Paper 2020-11, 17 April. 


\section{Figure 1. Realized U.S. Stock Market Volatility, January 1900 to April 2020}

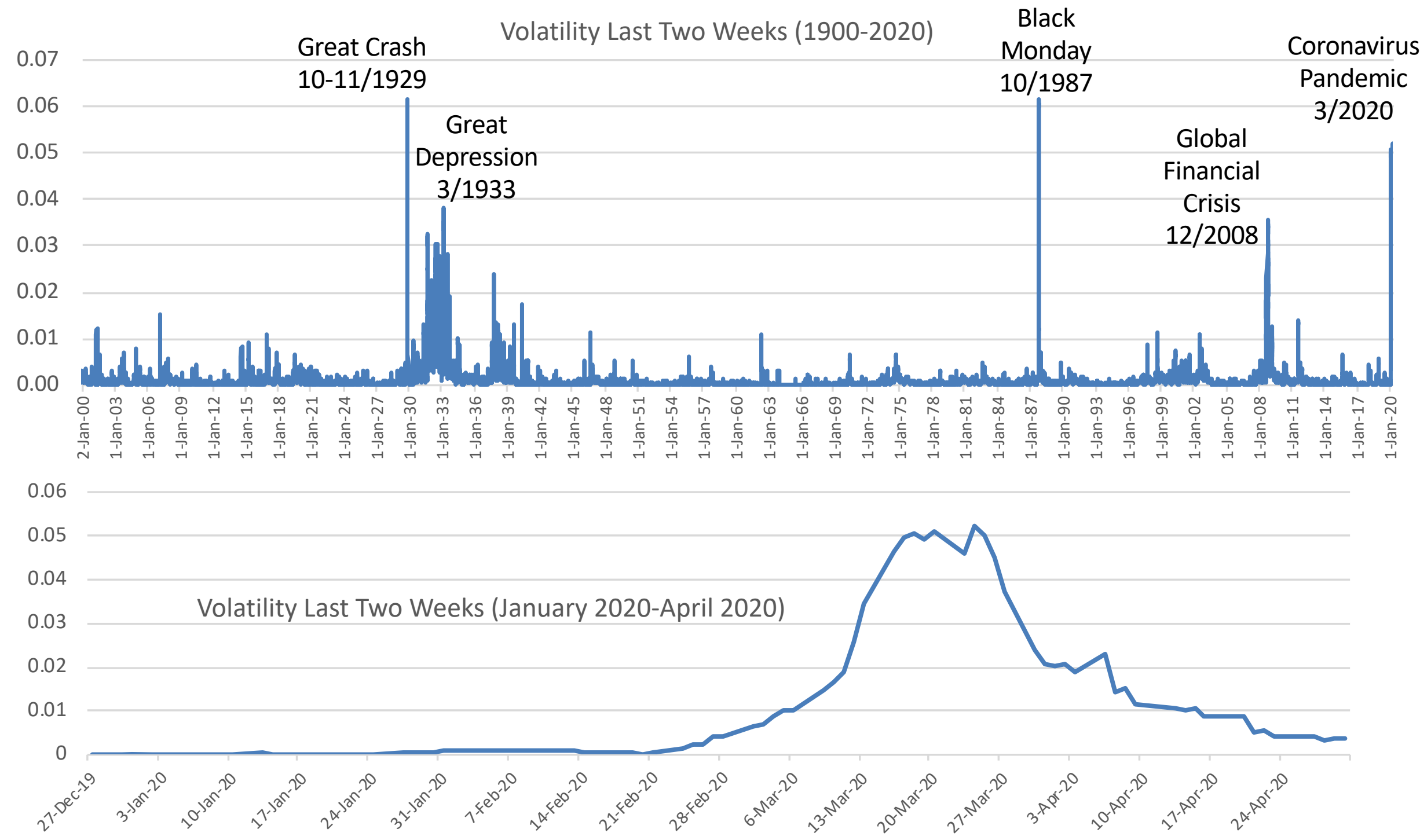

Notes: The sample period runs from 1/2/1900 to 4/30/2020. From December 1925 onwards, returns are computed using Yahoo Finance's 'adjusted close' series for the S\&P 500 (^GSPC). Before that, returns are from the Global Financial Data extension of the Dow Jones Index. In both panels, we calculate realized volatility as the sum of squared returns overthe past 10 trading days. 


\section{Table 1. The Unprecedented Stock Market Impact of the Coronavirus}

Number of Daily U.S. Number Attributed to Stock Market Jumps Greater than $|2.5 \%|$
Economic Fallout of Pandemics
Number Attributed

to Policy Responses

to Pandemics

2 January 1900 to

21 February 2020

1,116

0

0

24 February 2020

to 30 April 2020

27

13.4

10.4

Note: Tabulated from results in Baker, Bloom, Davis and Sammon (2020), who consider all daily jumps in the U.S. stock market greater than $2.5 \%$, up or down, since 1900 . They classify the reason for each jump into 16 categories based on human readings of nextday (or same-evening) accounts in the Wall Street Journal (and New York Times in 2020). Fractional counts arise when newspapers differ in their jump attribution or human readers differ in their classification of the attribution. Number Attributed to Economic Fallout of Pandemics includes jumps on 3/12 and 3/16 that a subset of coders classified as Macroeconomic Outlook. It's clear from reading these articles that the journalist regarded the deterioration in the Macroeconomic Outlook as due to the spread of the coronavirus. 


\section{Figure 2. Newspaper-Based Equity Market Volatility Tracker and the 30-Day VIX, January 1985 to April 2020}

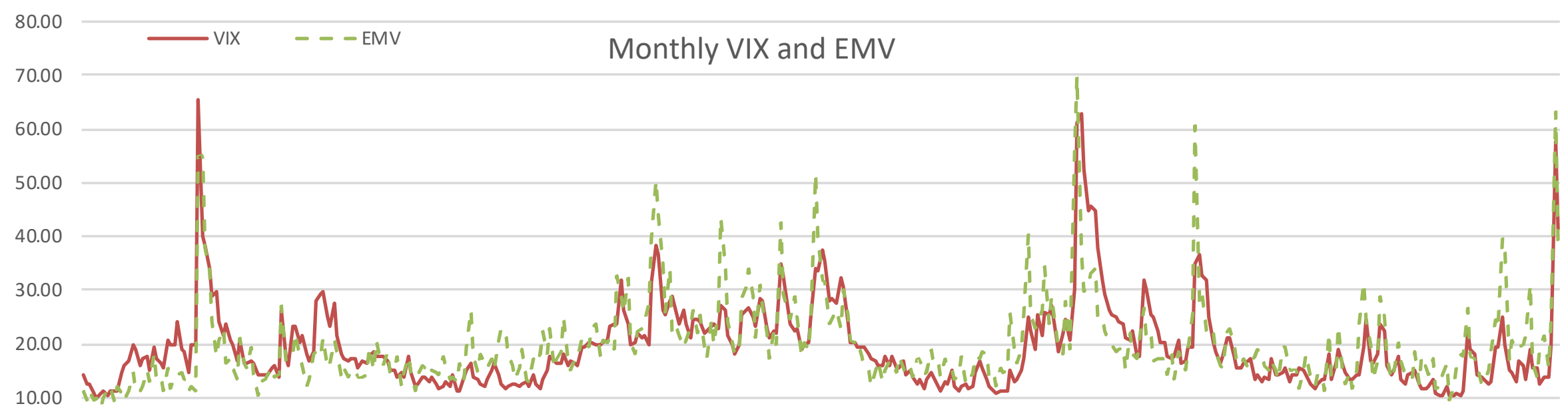

0.00

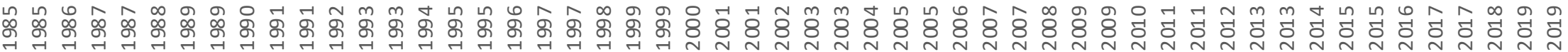

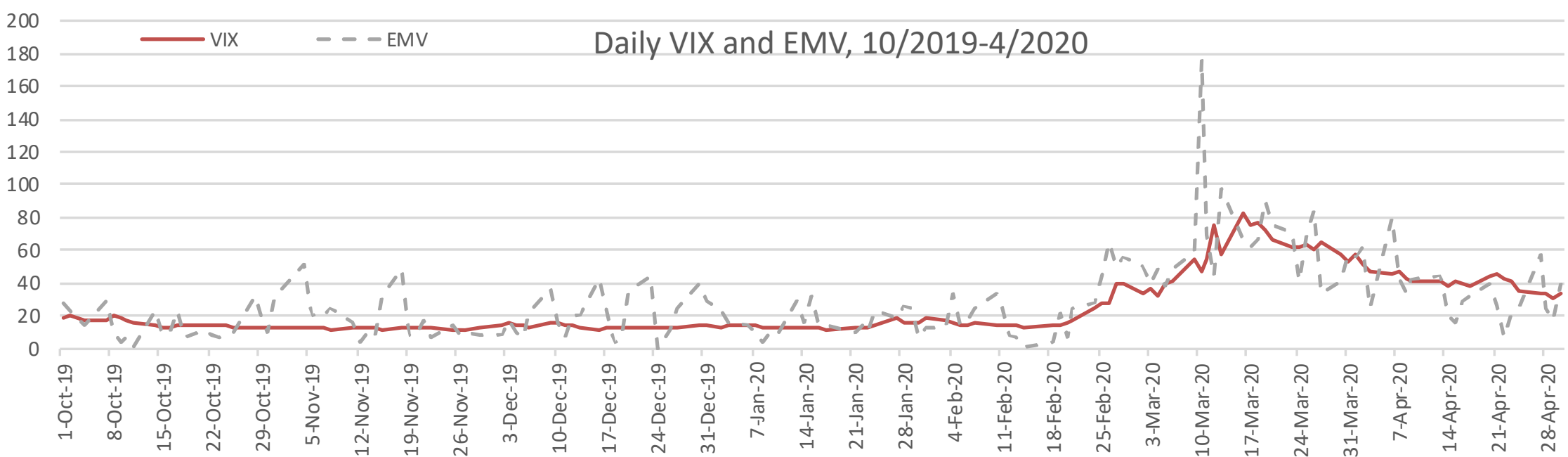

Notes: The Equity Market Volatility Tracker reflects the frequency of articles about stock market volatility in leading U.S. newspapers, as quantified by Baker, Bloom, Davis and Kost (2019). The 30-Day VIX is constructed as the monthly average of daily closing VIX values collected from Yahoo Finance. Bottom panel displays daily data for each series. 


\section{Figure 3. Infectious Disease EMV Index, Weekly and Monthly Data from 1985 to April 2020}

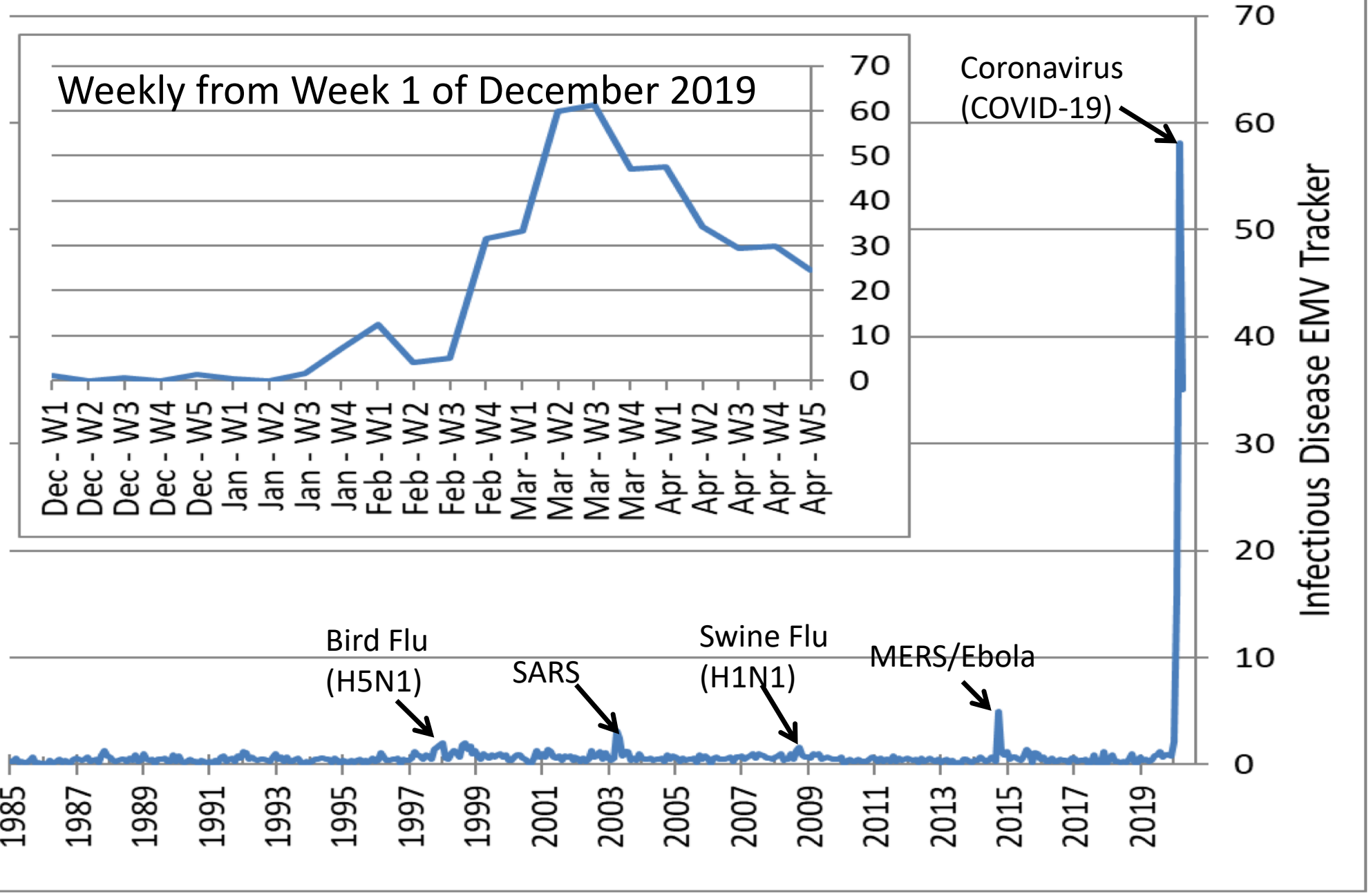

Notes: The Infectious Disease EMV Tracker is computed as the overall EMV tracker value multiplied by the share of EMV Articles that contain one or more of the following terms: epidemic, pandemic, virus, flu, disease, coronavirus, mers, sars, ebola., H5N1, H1N1. 


\section{Table 2. Stock Market Volatility in Selected Infectious Disease Episodes}

Average Values for the Indicated Time Period

\begin{tabular}{|c|c|c|c|c|}
\hline & Time Period & $\begin{array}{l}\text { (1) Infectious } \\
\text { Disease EMV } \\
\text { Tracker Level }\end{array}$ & $\begin{array}{l}\text { (2) \% of EMV Articles } \\
\text { with Infectious } \\
\text { Disease Terms }\end{array}$ & $\begin{array}{l}\text { (3) \% of EPU Articles } \\
\text { with Infectious } \\
\text { Disease Terms }\end{array}$ \\
\hline Bird Flu (H5N1) & $\begin{array}{l}\text { Nov-1997 to Nov- } \\
1998\end{array}$ & 1.36 & 4.52 & 8.00 \\
\hline SARS & April-August 2003 & 1.75 & 8.10 & 9.79 \\
\hline Swine Flu (H1N1) & March-May 2009 & 0.99 & 3.60 & 4.58 \\
\hline Ebola \& MERS & Oct-2014 to Jan-2015 & 2.06 & 10.62 & 12.80 \\
\hline \multirow{5}{*}{$\begin{array}{l}\text { Coronavirus } \\
\text { (Covid-19) }\end{array}$} & December 2019 & 0.79 & 3.68 & 6.42 \\
\hline & January 2020 & 2.11 & 13.45 & 7.43 \\
\hline & February 2020 & 15.74 & 64.38 & 32.62 \\
\hline & March 2020 & 58.13 & 91.73 & 94.33 \\
\hline & April 2020 & 35.01 & 92.13 & 98.65 \\
\hline Full Period & Jan 1985-Apr 2020 & 0.84 & 3.58 & 5.89 \\
\hline \multicolumn{5}{|c|}{$\begin{array}{l}\text { Notes: The Infectious Disease term set is \{epidemic, pandemic, virus, flu, disease, coronavirus, mers, sars, } \\
\text { ebola, H5N1, H1N1\}. We use the following newspapers in the analysis: Wall Street Journal, NY Times, } \\
\text { Chicago Tribune, Washington Post, LA Times, Boston Globe, Miami Herald, USA Today, SF Chronicle, Dallas }\end{array}$} \\
\hline
\end{tabular}




\section{Figure 4. Year-on-Year Change of Weekly Flight Frequency by Global Airlines, 6 January to 8 June 2020}

\section{$25 \%$}
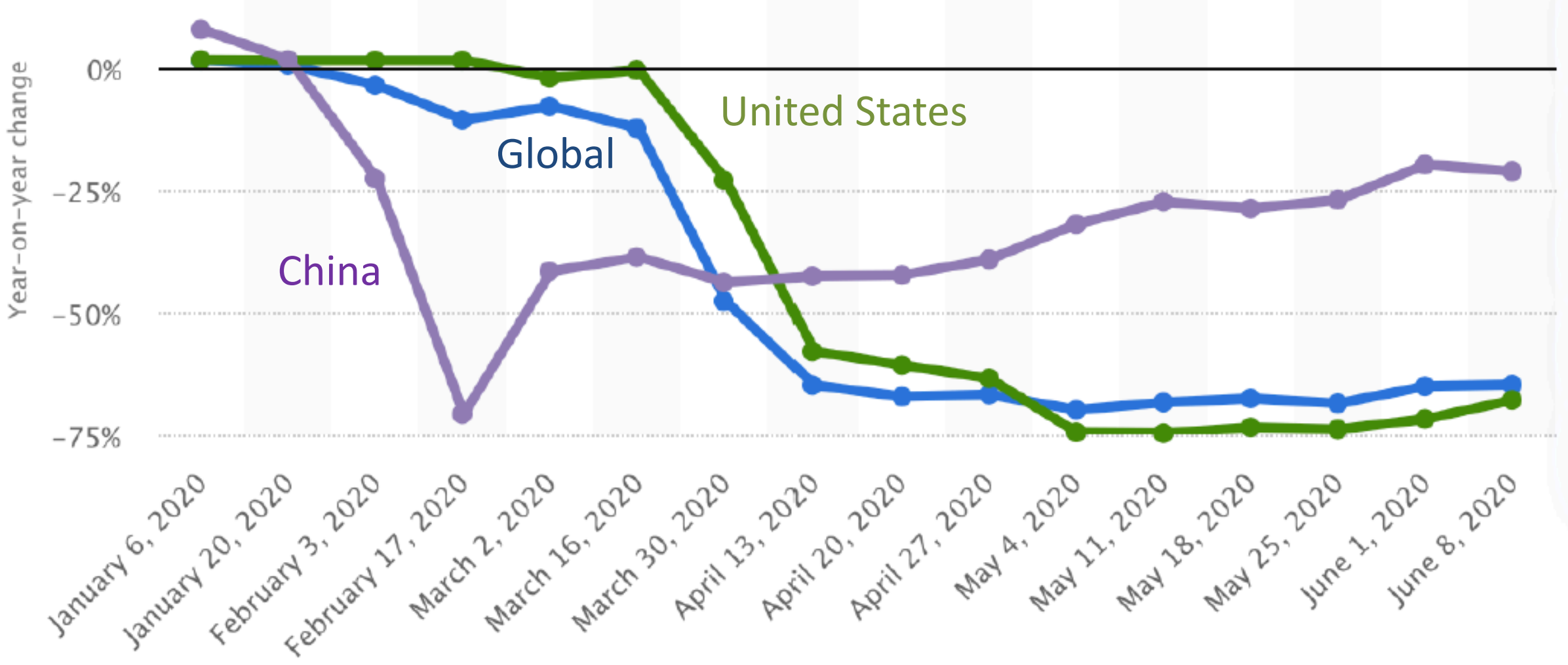

Notes: We obtained these data from Statista. The original source is the OAG Schedules Analyzer, published by OAG.com. 